\title{
Detoxification and Inflammation Control-“Hanshi Zufei Decoction", a Possible Effective Phytotherapy for Mild Cases by Coronavirus Disease 19
}

\author{
Jingjing Yang, Hualiang Chen* \\ Department of Pharmacy, Shaoxing Seventh People's Hospital, Shaoxing, Zhejiang Provence, China \\ Email: *chenxianzhi@tom.com
}

How to cite this paper: Yang, J.J. and Chen, H.L. (2020) Detoxification and Inflammation Control-"Hanshi Zufei Decoction", a Possible Effective Phytotherapy for Mild Cases by Coronavirus Disease 19. American Journal of Plant Sciences, 11, 1797-1813.

https://doi.org/10.4236/ajps.2020.1111129

Received: October 7, 2020

Accepted: November 27, 2020

Published: November 30, 2020

Copyright $\odot 2020$ by author(s) and Scientific Research Publishing Inc. This work is licensed under the Creative Commons Attribution-NonCommercial International License (CC BY-NC 4.0). http://creativecommons.org/licenses/by-nc/4.0/

\begin{abstract}
Object: This work explains the theoretical basis of "Hanshi Zufei Decoction" for the treatment of Coronavirus Disease 19 (COVID-19) through Western medical theories. Methods: We analyze the guideline of the "Diagnosis and Treatment Protocol for Novel Coronavirus Pneumonia" (Version I to Version VII) made by China, "Clinical Management of Severe Acute Respiratory Infection When Novel Coronavirus (2019-nCoV) Infection is Suspected-Interim Guidance" made by WHO, "Therapeutic Guidelines: Gastroenteropathy Section (Version V of Original)" and "Therapeutic Guidelines: Antibiotics Section (Version XV of Original)" published by Australia, and the origin of classical prescription of "Hanshi Zufei Decoction": "Shanghan Lun (Treatise on Febrile Diseases)", "Jinkui Yaolue (Synopsis of Golden Chamber)" and "Wenyi Lun (Treatise on Plague). We search the dictionary of traditional Chinese medicine (Version II) manually. Literature is searched from 2001 to 2020 on the Wiley online library. We conduct a comparative study on the traditional Chinese medicine (TCM) syndromes of "Hanshi Zufei Decoction", the pathogenesis and clinical manifestations of respiratory system diseases and acute gastrointestinal inflammation by COVID-19. And we conduct the pharmacological inquiry of "Hanshi Zufei Decoction". Results: The respiratory and gastrointestinal symptoms of COVID-19 and the basis of the "Hanshi Zufei Decoction" are basically considered to be consistent. "Hanshi Zufei Decoction" can relieve respiratory symptoms, protect gastrointestinal mucosa, promote intestinal emptying, and have anti-inflammatory and antibacterial effects in the form of clusters. The dosage form and dosage used are in line with the range of pharmacological activity of the drug. Conclusions: "Hanshi Zufei Decoction" may have a good performance in reducing toxicity
\end{abstract}


and controlling inflammation through intestinal emptying, and may play an active role in the treatment of COVID-19.

\section{Keywords}

Hanshi Zufei Decoction, COVID-19, Detoxification, Inflammation Control

\section{Introduction}

In more than 4 months of the outbreak of the novel coronavirus, there are confirmed cases in 215 countries and regions around the world, with a total of more than 8 million infections and more than 400,000 deaths. The epidemic has spread to South America and Africa where medical conditions are weak. Western developed countries have also reached a very serious point. With the deepening of research, a batch of promising drugs has withdrawn from the research process due to inaccurate efficacy. People are increasingly pinning their hopes on vaccines. However, the successful development of the vaccine will take time, and the spread of the disease is further expanding. According to current statistics, deaths account for about $5 \%$ of confirmed cases and about $49 \%$ are cured. Except for a small number of severe cases, most of the cured patients are mild cases, and a certain proportion of the remaining mild cases will be converted into severe. Reducing the amount of virus in the body of mild cases, reducing the damage of inflammatory factor outbreaks to organs, and preventing mild cases from turning into severe is one of the ideal ways to reduce the case inventory. "Hanshi Zufei Decoction" is one of the therapeutic schemes for severe acute respiratory tract infections caused by COVID-19 and one of the highly recommended phytotherapy in China. The author finds that "Hanshi Zufei Decoction" may have good performance in reducing toxicity and controlling inflammation.

The author tries to explain the possible value of "Hanshi Zufei Decoction" in the epidemic in an understandable way. The author explains the incomprehensible ancient medical texts of Chinese medicine in plain language and the source of "Hanshi Zufei Decoction" by adding and subtracting the classic prescription "Dayuan Yin (Membrane Source Opening Beverage)". The author conducts a comparative study on the clinical manifestations and indications of "Hanshi $\mathrm{Zu}$ fei Decoction" and treatment guidelines, and explores the correlation between them. The author tries to compare the pharmacological effects of a group of traditional Chinese medicines with the corresponding treatment solutions through the pharmacological inquiry, although the pharmacological effects of a single chemical component are different from the mixed decoction. The author links the treatment methods of "promoting, vomiting, descending and clearing" in "Moyuan Lun (Theory of Membranous Origin)" with the treatment of COVID-19, and tries to explain the effectiveness and scientificity of "Hanshi Zufei Decoction". The author hopes that this article can bring some help to the treatment of COVID-19. 


\section{Material and Methods}

\subsection{Material}

Research refers to guideline of the "Diagnosis and Treatment Protocol for Novel Coronavirus Pneumonia" (Version I to Version VII) made by China, "ClinicalManagement of Severe Acute Respiratory Infection When Novel Coronavirus (2019-nCoV) Infection is Suspected-Interim Guidance" made by WHO, "Therapeutic Guidelines: Gastroenteropathy Section (Version V of Original)" and "Therapeutic Guidelines: Antibiotics Section (Version XV of Original)" published by Australia.

"Hanshi Zufei Decoction" is derived from the classic treatise "Wenyi Lun (Treatise on Plague)" which refers to the second edition of "Wenyi Lun (Treatise on Plague)", published by China pharmaceutical science and technology press, edited by $\mathrm{Wu}$ Youxing and proofread by $\mathrm{He}$ Yongxiao, and "Wenyi Lun Pingzhu" which is published by people's medicine publishing house, annotated by Zhejiang institute of traditional Chinese medicine.

According to the clinical manifestations, the treatment of "Hanshi Zufei Decoction" can be divided into respiratory system and gastrointestinal system. Referring to the different academic thoughts of Zhang Zhongjing's treatise "Shanghan Lun (Treatise on Febrile Diseases)", "Jinkui Yaolue (Synopsis of Golden Chamber)" and Wu Youxing's treatise "Wenyi Lun (Treatise on Plague)", this paper studies the basic theory and drug composition of "Hanshi Zufei Decoction".

The dictionary of traditional Chinese medicine (Version II) is searched manually, which is published by Shanghai science and technology publishing house and redacted by Nanjing University of Traditional Chinese Medicine. The pharmacology of prescription drugs in dictionary is confirmed and the dictionaryis cited until 2001.

Literature search is performed on scientific databases including Wiley online library, CNKI online library, PubMed and others.

\subsection{Methods}

A comparative study on the therapeutic options and indications among "Hanshi Zufei Decoction" and COVID-19 is conducted. The retrieval results of pathological etiology, disease symptoms and therapeutics of TCM are compared with the western medicine. Pharmacological inquiry of "Hanshi Zufei Decoction" is carried out. The retrieval results of the pharmacology of TCM are compared with the western medicine.

\section{Result}

\subsection{The Evidences of Chinese Herbal "Hanshi Zufei Decoction"}

The clinical manifestations of "Hanshi Zufei Decoction" include low fever, low body temperature, or no heat, dry cough, low sputum, fatigue, chest tightness and nausea. The tongue is pale or red, and the coating is white or greasy, and the 
veins are pulsating. This formula is suitable for mild cases.

Wu Youxing proposed classical "Dayuan Yin (Membrane Source Opening Beverage)" prescription to dispel evil Qi lurking in the membrane. He believes that Binglang (Areca-nut) can promote digestion and purgation to get rid of the toxin. Houpu (Magnolia officinalis) can break away the accumulated evil Qi and Caoguo (Amomum tsao-ko) caneliminate the pathogen lying in the membrane. Above three herbs worked together to defeat the evil Qi and keep it away from the membrane, so it is called "Dayuan Yin (Membrane Source Opening Beverage)". It is seemed dampness by TCM. Cangzhu (Atractylodes rhizome), Huoxiang (Agastache rugosus), Chenpi (Tangerine peel) and Houpu (Magnolia officinalis) have the effects of removing dampness. The properties of Huoxiang (Agastache rugosus), Mahuang (Ephedra), Qianghuo (Notopterygium) and Shengjiang (Ginger) are pungent and warm, and are usually used to dispel dampness and relieve exterior symptoms. Fresh Mahuang (Ephedra) has the effects of diaphoresis and diuresis, and the effect can be strengthened when used with Shengjiang (Ginger). It also can moisten lung and relieve cough when used with Chenpi (Tangerine peel). With the cooperation of all kinds of herbs, the Decoction can dissipate dampness to relieve the exterior, and release and lower lung Qi.

\subsection{The Pharmacological Basis of "Hanshi Zufei Decoction"}

Recommended prescription: Cangzhu (Atractylodes rhizome) 15 g, Chenpi (Tangerine peel) $10 \mathrm{~g}$, Houpu (Magnolia officinalis) $10 \mathrm{~g}$, Huoxiang (Agastache rugosus) $10 \mathrm{~g}$, Caoguo (Amomum tsao-ko) $6 \mathrm{~g}$, Sheng Mahuang (Raw Ephedra) $6 \mathrm{~g}$, Qianghuo (Notopterygium) $10 \mathrm{~g}$, Shengjiang (Ginger) $10 \mathrm{~g}$, Binglang (Areca-nut) $10 \mathrm{~g}$.

The volatile oil from Cangzhu (Atractylodes rhizome) is the predominantly active constituents and the extraction yield is $1.33 \%-4.06 \%$ due to the different varieties [1]. It has strong activity againstbacteria and fungus, and the bacteriostatic effect increases with the increasing concentration. It's essential oil can significantly inhibit E. coli (Escherichia coli), P. aeruginosa (Pseudomonas aeruginosa), Serratia, S. aureus (Staphylococcus aureus) and B. subtilis (Bacillus subtilis), with the minimum inhibitory concentrations (MIC) ranging from 0.5 to 2.0 $\mathrm{mg} / \mathrm{mL}$, respectively [2] [3]. Moreover, its extract has conspicuous inhibitory effect on inflammatory factors. Liu et al. clarified that it could inhibit the production of tumor necrosis factor- $\alpha$ (TNF- $\alpha$ ), interleukin (IL)-1 $\beta$, IL-17, and IL-6 in the joints of the rats with collagen-induced arthritis (CIA). Meanwhile, it has remarkable protective effect on hepatocyte injury induced by paracetamol [4] [5]. Results from a previous study demonstrated that it produced an antiulcer effect at similar potency as the reference drug omeprazole at a certain dose. Its action mechanism on antiulcer activity might be mediated through inhibition of gastric secretion and reduction of effects on histamine-induced ulceration and stress-induced ulceration [6] [7] [8]. 
Chenpi (Tangerine peel) is a kind of Chinese medicine with the same medicine and food, which is used widely in clinical practice to treat nausea, vomiting, indigestion, anepithymia, cough and inflammation [9] [10]. Experiments have demonstrated that it has a dual function in promoting gastrointestinal motility and inhibiting intestinal smooth muscle contraction [11]. Up to now, approximately 140 chemical ingredients have been isolated and identified from it, including volatile oil, flavonoids and alkaloids. As one kind of flavonoids, Hesperidin inhibits inflammatory cell infiltration and mucus hypersecretion in a mouse allergic asthma model [12]. Its powder reduces the expression of pro-inflammatory cytokines in colitis mice, and ameliorates intestinal barrier defects and inflammation. The dried peel powder of it inhibits microglial activation in the hippocampus and the phosphorylation of tau in the hippocampal neurons, reflecting its anti-inflammatory and neuroprotective effects [13] [14].

Houpu (Magnolia officinalis) has many pharmacological activities including anti-inflammatory, antibacterial, gastrointestinal protection and gastrointestinal motility promotion [15] [16] [17]. Magnolol and honokiol are its main active ingredients. Lin et al found that treatment with magnolol greatly improved the pathological features of acute lung injury (ALI) evidenced by reduction of lung edema, polymorphonuclear neutrophil infiltration, ROS production, the level of pro-inflammatory cytokines in bronchoalveolar lavage fluid [18]. Inflammation in Lungs plays a critical role in the pathogenesis of asthma and chronic obstructive pulmonary disease. Magnolol inhibits the inflammatory in lung epithelial A549 cells by blocking the ICAM-1 (intercellular adhesion molecule-1), NF-кB (Nuclear factor kappa B) and MAPK (Mitogen-activated protein kinase) signaling pathways [19]. In addition, Yang et al revealed that honokiol liposomal could induced apoptotic and antitumor activities in four xenograft models generated using non-small cell lung cancer [20].

Huoxiang (Agastache rugosus), a medicinal plant belonging to the family Lamiaceae, has been used to treat cholera, vomiting miasma and other intestinal disorders. Pharmacological investigation revealed that it possesses a variety of effects, including antibacterial, antioxidant, cytoprotective activity [21] [22]. Moreover, it can obviously promote gastric emptying and speed up the propulsive movement of gastrointestinal tract to maintain normal gastrointestinal function of rats with the syndrome of damp retention in middle-jiao [23]. As a main aromatic ingredient of Huoxiang (Agastache rugosus), thymoquinone can remit acetaminophen overdose-induced acute liver injury and inflammation via regulation of JNK (c-Jun N-terminal kinase) and AMPK (AMP-activated protein kinase ) signaling pathway [24].

The essential oils of Caoguo (Amomum tsao-ko) exhibits moderate to potent broad-spectrum antimicrobial activity against both gram-positive and gramnegative bacteria. Among the test stains, the MIC and MBC values of Staphylococcus epidermidis, Propionibacterium acnes, Pseudomonas aeruginosa and Candida albicans are $2.94-5.86 \mathrm{mg} / \mathrm{mL}$ and $5.8-11.73 \mathrm{mg} / \mathrm{mL}$, respectively 
[25]. The isolated products in Caoguo (Amomum tsao-ko), pyranflavanones and pyranchalcones, had a significant inhibitory effect on the NO production and exhibited $\mathrm{IC}_{50}$ values ranging from 10.6 to $41.5 \mu \mathrm{M}$. Its methanol extract strongly inhibits lipopolysaccharide-induced NO production by activating the ROS/ MAPKs/Nrf2-mediated HO-1 signaling pathway, and supports its inflammatory activity [26] [27].

Mahuang (Ephedra) is traditionally used to treat cold, bronchial asthma, cough, fever, flu and edema [28] [29]. It has become a natural product source of alkaloids, including ephedrine, pseudoephedrine, norpseudoephedrine, cathine, methylephedrine and methyl-pseudoephedrine [30]. It produces significant cardiovascular responses after a single dose, thereby increasing heart rate and blood pressure [31]. Ephedrine, the main active element of Mahuang (Ephedra), is approved for the treatment of clinically significant hypotension perioperatively by FDA [32]. In addition, methanolic extract of Mahuang (Ephedra) ameliorates cisplatin-induced nephrotoxicity and hepatotoxicity through reducing oxidative damage [33].

Qianghuo (Notopterygium) is widely used in anti-inflammatory, anti-oxidation, anti-arrhythmia, antibacterial, anti-cancer cell proliferation and other treatments [34] [35]. Isoimperatorin (IO), a furanocoumarin isolated from Qianghuo (Notopterygium), shows prominent activity against mycobacterium tuberculosis and nematodes [36] [37]. Furthermore, IO effectively inhibits ovalbumin-induced inflammatory cell infiltration and mucus production to relieve symptoms of asthma [38]. IO is able to induce the apoptosis of the SGC-7901 human gastric cancer cell line through the mitochondria-mediated pathway [39].

In various traditional system of medicine, Shengjiang (Ginger) is used to be a carminative, diaphoretic, antispasmodic, astringent, appetite stimulant and anti-inflammatory agent [40]. Studies have shown that it prevents nausea or emesis resulting from pregnancy, motion sickness, postoperation chemotherapy and radiation, which verifies its broad-spectrum antiemetic effects [41] [42]. Fresh Shengjiang (Ginger) has been proved to have antiviral activity against human respiratory syncytial virus (HRSV), and it dose-dependently inhibits HRSV-induced plaque formation in human respiratory tract cell lines [43]. In addition to this, studies have confirmed that it availably ameliorates high-fat diet induced hyperlipidemia via decreasing serum cholesterol and triglycerides [44] [45]. Zingerone, a phenolic found in Shengjiang (Ginger), has been reported to possess anti-factor $\mathrm{Xa}$ (Fxa) and anti-platelet aggregation activities, thereby preventing further development of atherosclerosis [46].

Binglang (Areca-nut) contains a various of chemical components, such as alkaloids, tannins, flavones, triterpenes, steroids and fatty acids, and has many pharmacological functions including antiparasitic, anti-depression, antioxidant, antibacterial, anti-inflammatory and promoting digestion [47] [48]. The water extracts of it remarkably improves gastrointestinal motility in rabbits via stimulation of the $\mathrm{M}$ receptor and $\mathrm{Ca}^{2+}$ channel [49]. Study on the ethanol extracts of it shows clear hepatoprotective effects on carbon tetrachloride-induced liver in- 
jury in rats, the mechanisms might be associated with decreasing serum aminotransferase (ALT), aspartate aminotransferase (AST) and hepatic malondialdehyde (MDA) [50]. Furthermore, it possesses potential antidepressant function through the elevation of serotonin and noradrenaline in the hippocampus of rats [51]. The function and pharmacological basis of the herbs are shown in Table 1.

\subsection{The Corresponding Relationship between the Herbs of "Hanshi Zufei Decoction" and the Important Organ Symptoms of COVID-19}

"Hanshi Zufei Decoction" is mainly used for mild cases. The clinical manifestations of mild cases are dry cough, low phlegm, chest tightness, dyspepsia, emesis, loose stool, low fever or no heat, which means that respiratory and gastrointestinal systems are primarily disrupted by pathogens. Therefore, the symptomatic treatment of TCM is generally reflected in the respiratory and gastrointestinal systems. As shown in Table 2, Houpu (Magnolia officinalis), Chenpi (Tangerine peel), Caoguo (Amomum tsao-ko), Mahuang (Ephedra), Huoxiang (Agastache rugosus), Qianghuo (Notopterygium) are acted on the respiratory system to relieve cough, expectorate and asthma. For gastrointestinal systems, Mahuang (Ephedra), Chenpi (Tangerine peel), Caoguo (Amomum tsao-ko), Binglang (Areca-nut) are combined together to promote the secretion of digestive juices and gastric emptying. On this basis, the addition of Cangzhu (Atractylodes rhizome), Houpu (Magnolia officinalis), Shengjiang (Ginger) can promote intestinal peristalsis, thereby improving the digestive function of gastrointestinal tract. Moreover, Houpu (Magnolia officinalis) and Cangzhu (Atractylodes rhizome) can also effectively repair gastrointestinal injuries and maintain gastrointestinal digestive function. Shengjiang (Ginger) and Qianghuo (Notopterygium) have anti-vomiting and anti-diarrhea activities, respectively. In brief, "Hanshi Zufei Decoction" can improve the defense function of respiratory digestive systems through the combination of various herbs, and obviously relieve the respiratory and digestive symptoms of moderate cases.

\subsection{Important Laboratory Parameters of COVID 19 and the Chinese Herbs Medicine Functional Groups with Clear Pharmacological Support}

During the treatment of COVID-19, persistent inflammation is common in confirmed patients, which is manifested as elevated laboratory test parameters CRP (C-reactive protein), WBC (White blood cell count), TNF (Tumor necrosis factor), PCT (Procalcitonin). In addition, vascular occlusion, liver injury, elevation of d-dimer, AST (Aspartate aminotransferase) and ALT (Alanine aminotransferase) may also occur in some cases (Table 3). "Hanshi Zufei Decoction" has therapeutic effect on the above symptoms. All herbs of it can alleviate persistent inflammation. Except Mahuang (Ephedra) and Chenpi (Tangerine peel), the remaining herbs in the prescription have antibacterial activity for bacterial infection. For thrombotic diseases, Houpu (Magnolia officinalis), Huoxiang 
Table 1. The function and pharmacologic basis on herbs of "Hanshi Zufei Decoction".

\begin{tabular}{|c|c|c|c|c|c|c|c|c|c|c|c|}
\hline 营 & 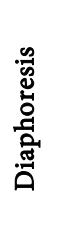 & 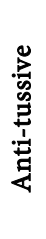 & 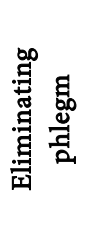 & 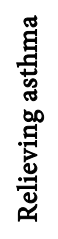 & 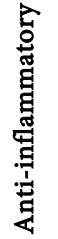 & 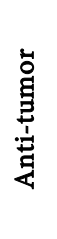 & 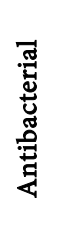 & 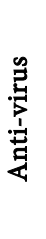 & 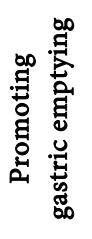 & 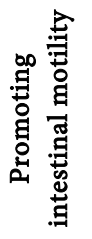 & 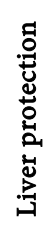 \\
\hline Mahuang (Ephedra) & + & & & ++ & + & & & & & + & \\
\hline Huoxiang (Agastache rugosus) & & + & + & + & + & & ++ & + & & + & \\
\hline Houpu (Magnolia officinalis) & & & & + & ++ & ++ & ++ & & & + & + \\
\hline Cangzhu (Atractylodes rhizome) & & & & & ++ & + & ++ & + & & ++ & ++ \\
\hline Caoguo (Amomum tsao-ko) & & & + & & + & & + & & + & + & \\
\hline Chenpi (Tangerine peel) & & + & ++ & + & + & + & & & & + & \\
\hline Shengjiang (Ginger) & & & & & + & & + & & & + & + \\
\hline Qianghuo (Notopterygium) & & & & + & + & + & + & + & & & \\
\hline Binglang (Areca-nut) & & & & & + & & + & & ++ & ++ & \\
\hline
\end{tabular}

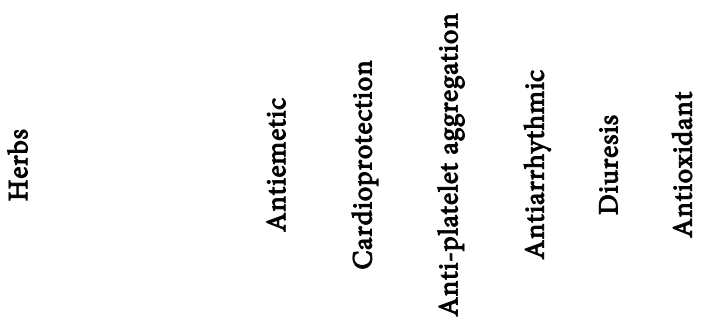

$$
\text { huang (Ephedra) }
$$

Huoxiang (Agastache rugosus)

Houpu (Magnolia officinalis)

Cangzhu (Atractylodes rhizome)

Caoguo (Amomum tsao-ko)

Chenpi ( Tangerine peel)

Shengjiang (Ginger)

Qianghuo (Notopterygium)

Binglang (Areca-nut)

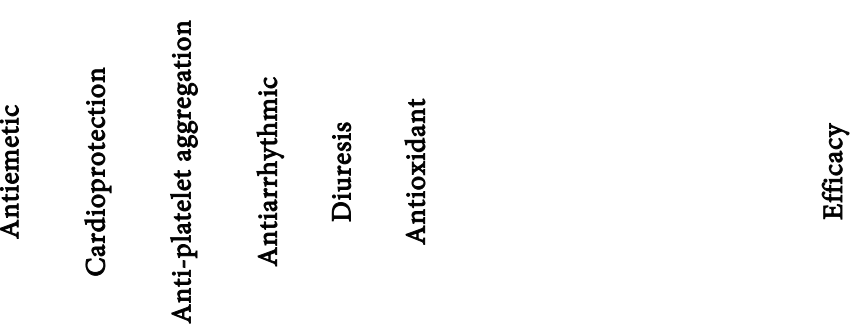

突

Inducing sweating to relieve exterior syndrome, freeing lung and relieving asthma, inducing diuresis to alleviate edema

Resolving dampness, preventing vomiting,

relieving summer-heat

Eliminating dampness and phlegm, lowering qi to remove fullness

Drying damp strengthening spleen, expelling wind and removing cold

Drying dampness for warming stomach, eliminating phlegm for preventing malaria

Regulating qi-flowing for strengthening spleen, eliminating dampness and phlegm

Relieve exterior syndrome to dispel cold, warming stomach for preventing vomiting, warming lung for relieving a cough, detoxication

Relieve exterior syndrome to dispel cold, dispelling wind and dampness, acesodyne

Killing parasites for removing food retention, activating qi to induce diuresis, preventing malaria 
Table 2. Corresponding relationship between the pharmacological effect of the Chinese herbs and symptoms of COVID-19 on important organs.

\begin{tabular}{|c|c|c|c|c|}
\hline Organ & Symptom & Occurrence \% & Treatment & The name of Chinese herbs \\
\hline \multirow{2}{*}{ Body surface } & \multirow{2}{*}{ Fever } & \multirow{2}{*}{91.7} & Antipyretic & Ephedra, Ginger, Notopterygium \\
\hline & & & Sweating & Ephedra \\
\hline \multirow{3}{*}{$\begin{array}{l}\text { Respiratory } \\
\text { system }\end{array}$} & Cough & 75 & Relieve cough & Agastache rugosus, Tangerine peel \\
\hline & Expectoration & & Eliminating phlegm & $\begin{array}{l}\text { Agastache rugosus, Tangerine peel, } \\
\text { Amomum tsao-ko }\end{array}$ \\
\hline & $\begin{array}{l}\text { Chest } \\
\text { distress/dyspnea }\end{array}$ & 36.7 & Anti-asthmatic & $\begin{array}{l}\text { Ephedra, Agastache rugosu, Magnolia officinalis, } \\
\text { Tangerine peel, Notopterygium }\end{array}$ \\
\hline \multirow{8}{*}{$\begin{array}{l}\text { Gastrointestinal } \\
\text { system }\end{array}$} & \multirow{6}{*}{$\begin{array}{l}\text { Gastrointestinal } \\
\text { disorders }\end{array}$} & \multirow[t]{6}{*}{39.6} & $\begin{array}{l}\text { Promoting the secretion } \\
\text { of gastrointestinal } \\
\text { digestive fluids }\end{array}$ & Agastache rugosu, Tangerine peel, Areca-nut \\
\hline & & & $\begin{array}{l}\text { Promoting gastric } \\
\text { emptying }\end{array}$ & Amomum tsao-ko, Areca-nut \\
\hline & & & Repairing gastric damage & $\begin{array}{l}\text { Magnolia officinalis, Atractylodes rhizome, } \\
\text { Tangerine peel, Ginger, Notopterygium }\end{array}$ \\
\hline & & & $\begin{array}{l}\text { Promoting } \\
\text { gastrointestinal peristalsis }\end{array}$ & $\begin{array}{l}\text { Atractylodes rhizome, Tangerine peel, Magnolia } \\
\text { officinalis, Agastache rugosu, Amomum tsao-ko, } \\
\text { Ephedra, Ginger, Areca-nut }\end{array}$ \\
\hline & & & $\begin{array}{l}\text { Repairing intestinal } \\
\text { damage }\end{array}$ & Agastache rugosu, Magnolia officinalis \\
\hline & & & Promoting bile secretion & Tangerine peel, Ginger \\
\hline & \multicolumn{2}{|l|}{ Loose stool } & Anti-diarrhea & Notopterygium \\
\hline & Emesis & 5 & Antiemetic & Ginger \\
\hline \multirow{2}{*}{$\begin{array}{l}\text { Hepatobiliary } \\
\text { system }\end{array}$} & & & Liver protection & Magnolia officinalis, Atractylodes rhizome, Ginger \\
\hline & & & Cholagogue & Tangerine peel, Ginger \\
\hline Urinary system & & & Diuresis & Ephedra, Atractylodes rhizome \\
\hline \multirow[t]{2}{*}{ Blood system } & & & Anti-platelet aggregation & $\begin{array}{l}\text { Magnolia officinalis, Agastache rugosu, Ginger, } \\
\text { Notopterygium }\end{array}$ \\
\hline & & & Blood circulation & Tangerine peel, Ginger, Notopterygium \\
\hline \multirow{3}{*}{$\begin{array}{l}\text { Cardiovascular } \\
\text { system }\end{array}$} & & & Heart protection & Ephedra, Ginger, Notopterygium \\
\hline & & & Antiarrhythmic & Atractylodes rhizome, Notopterygium \\
\hline & & & Pseudoepinephrine effect & Ephedra, Magnolia officinalis, Atractylodes rhizome \\
\hline \multirow[t]{2}{*}{ Central system } & \multirow[t]{2}{*}{ Abdominal pain } & \multirow[t]{2}{*}{5.8} & Analgesia & $\begin{array}{l}\text { Magnolia officinalis, Agastache rugosu, } \\
\text { Amomum tsao-ko, Ginger, Notopterygium }\end{array}$ \\
\hline & & & Anti-depression & Magnolia officinalis, Areca-nut \\
\hline
\end{tabular}

(Agastache rugosus), Shengjiang (Ginger) and Qianghuo (Notopterygium) have antiplatelet aggregation activity. Furthermore, Houpu (Magnolia officinalis), Cangzhu (Atractylodes rhizome) and Shengjiang (Ginger) have live protection for liver injury. 
Table 3. Important laboratory parameters of COVID-19 and the Chinese herbs medicine functional groups with clear pharmcology support.

\begin{tabular}{|c|c|c|c|}
\hline $\begin{array}{l}\text { Laboratory test } \\
\text { parameters }\end{array}$ & Pathology & Pharmacological effect & The name of Chinese herbs \\
\hline $\mathrm{CRP} \uparrow$ & & & Ephedra, Agastache rugosus, Magnolia officinalis, Atractylodes \\
\hline $\mathrm{WBC} \uparrow$ & & Anti-inflammatory & rhizome, Amomum tsao-ko, Tangerine Peel, Ginger, \\
\hline $\mathrm{IL}-6 \uparrow$ & $\begin{array}{l}\text { Persistent } \\
\text { inflammation }\end{array}$ & & Notopterygium, Areca-nut \\
\hline Anti-tumor factors $\uparrow$ & & Anti-tumor factor & $\begin{array}{l}\text { Magnolia officinalis, Atractylodes rhizome, Notopterygium, } \\
\text { Tangerine peel }\end{array}$ \\
\hline $\mathrm{PCT} \uparrow$ & Bacterial infection & Antibacterial & $\begin{array}{l}\text { Agastache rugosus, Magnolia officinalis, Atractylodes rhizome, } \\
\text { Amomum tsao-ko, Ginger, Notopterygium, Areca-nut }\end{array}$ \\
\hline D-Dimer $\uparrow$ & Thrombus & Anticoagulation & Agastache rugosus, Magnolia officinalis, Ginger, Notopterygium \\
\hline $\mathrm{ALT} / \mathrm{AST} \uparrow$ & Livet injury & Liver protection & Magnolia officinalis, Atractylodes rhizome, Ginger \\
\hline
\end{tabular}

Note: CRP: C-reactive protein; WBC: White blood cell count; IL-6: Interleukin-6; PCT: Procalcitonin; AST: Aspartate aminotransferase, ALT: Alanine aminotransferase, LDH: Lactate dehydrogenase.

\subsection{The Relationship between Pharmacological Effect and Effective Dose}

As the main constituents of Houpu (Magnolia officinalis), magnolol and honokiol show remarked bactericidal activity against Streptococcus mutans planktonic cells and inhibits biofilm formation in a dose-time dependent manner. The MIC of magnolol and honokiol for Streptococcus mutans are $10,10 \mu \mathrm{g} / \mathrm{mL}$, respectively [52]. Besides, they could improve the gastric emptying of a semi-solid meal and intestinal propulsion in mice at the dose of $5 \mathrm{mg} / \mathrm{kg}$ [53]. The total content of magnolol and honokiol in medicinal material calculated by dried products should not be less than $2 \%$ in Chinese Pharmacopoeia (Version 2010). The dosage of Houpu (Magnolia officinalis) in the prescription is $10 \mathrm{~g}$, which should reach or even exceed the effective minimum effective dose. The MIB of essential oil for Escherichia coli, Pseudomonas aeruginosa, Salmonella enterica, Staphylococcus aureus and Bacillus subtilis is between $0.5-2.0 \mathrm{mg} / \mathrm{mL}$. The extract yield of volatile oil ranges from $1.33 \%$ to $4.06 \%$. Intragastric treatment with an aqueous extract $(250 \mathrm{mg} / \mathrm{kg})$ significantly improved delayed gastric emptying in rats induced by $\mathrm{N}(\mathrm{G})$-nitro-L-arginine [54]. Therefore, it can reach bacteriostatic concentration and promote gastrointestinal propulsion at a dose of $10 \mathrm{~g}$. Meanwhile, the quality and dosage of Chinese herbal medicine are also regulated in Chinese Pharmacopoeia.

\section{Discussion}

\subsection{Anti-Epidemic Thought of Wenyi Lun (The Theory of Plague)}

$\mathrm{Wu}$ Youxing lived in the late Ming Dynasty when disasters were frequent. Social contradictions, national contradictions, war, corvee and disaster situation made the disaster control more difficult to implement. The epidemic had reached the level of several times a year, resulting in a large number of deaths. On the basis 
of predecessors' accumulation and through his own observation and practice, $\mathrm{Wu}$ Youxing realized that the epidemic was not caused by the change of seasons and climate, but because it was infected with a kind of evil Qi, which was an independent substance. It was transmitted through the mouth and nose, and also through contact. Wu Youxing put forward the theory of "membranous origin" (Moyuan Lun) in "Wenyi Lun (The Theory of Plague)". It was believed that after entering the human body from the mouth and nose, the evil Qi first absorbed on the membrane origin. The membrane origin was very close to the lung, stomach and intestines. It was not in the viscera or in the cavity of the human body, but in the "membrane origin" that couldn't be ignored. He believed that everyone behaved differently after people were infected with evil Qi. Some people did not get sick when they were infected. Others were mild or serious. This was related to personal physical condition and living conditions. If the disease was not controlled, the mild cases would turn into severe cases, and then affected the lung function, gastrointestinal function, heart and kidney function, which would cause the disease to develop into an uncontrollable and endanger life. $\mathrm{Wu}$ Youxing proposed the treatment method of "promoting, vomiting, lowering and clearing", which made the evil Qi leave the human body through vomiting and promoting intestinal excretion. These objects of "vomiting" and "lowering" include toxin, retention of food and fecal accumulation caused by evil Qi.

\subsection{Gastroenteric Function}

Modern pharmacology shows that the COVID-19 virus (SARS-2) can bind with the angiotensin-2 receptor of the gastrointestinal tract, infect gastrointestinal tract and promote the outbreak of inflammatory factors, thus blocking the excretion function of the gastrointestinal tract. Stagnation and accumulation of toxins in the intestine will further affect the cardiac and renal functions. The prescription clearly reflects Wu's treatment idea of accelerating the efflux of the evil Qi through the gastrointestinal tract and reducing the retention time in the body. On the one hand, "Hanshi Zufei Decoction" can effectively establish the protective layer of the gastrointestinal mucosa, promote gastrointestinal peristalsis and emptying, and quickly remove viruses, inflammatory factors and toxins from the body, so as to reduce further damage. On the other hand, it can enhance the digestion and absorption function of the gastrointestinal tract to provide nutritional support, improve the body's own immunity and promote the recovery of the body. In this sense, promoting intestinal emptying may have a positive significance in reducing the virus.

\subsection{Anti-Inflammatory Drug Combination}

The monitoring of clinical inflammatory factors is an important basis for judging disease progression. The main inflammatory factors include CRP, D-dimer, PCT, total number and subsets of lymphocytes, ferritin, IL-4, IL-6, IL-10, TNF-a, etc. The focus in the later stage of COVID-19 infection is the eruption of in- 
flammatory factors. "Hanshi Zufei Decoction" can control the inflammatory storm of cytokines, shorten the course of the disease, and avoid the adverse reactions and complications caused by the long-term use of glucocorticoids.

\subsection{Secondary Infection}

COVID-19 is a viral infection. Prophylactic use of antibiotics is not recommended for mild and general cases. Severe cases need to be cautious in deciding whether to use antibiotics prophylactically. Viral infection can lead to the decline of cellular immunity, and the use of glucocorticoids or broad-spectrum antibiotics can lead to a secondary infection. Therefore, bacteria and fungi are continuously detected in the lungs of COVID-19 cases. The use of plant antibiotics can avoid the abuse of antibiotics. At the same time, "Hanshi Zufei Decoction" also inhibits the growth of bacteria and fungi and reduces the occurrence of secondary infection, which is equivalent to preventive medication.

\subsection{Effectiveness}

The research on the pharmacological effects of traditional Chinese medicine is mainly aimed at a single active ingredient. The effectiveness of a single active ingredient does not indicate the effectiveness of a single Chinese herbal medicine. Group herb medicines may increase the toxicity of the medicine and reduce the effective effect due to the interaction of the medicine. The problem is that everyone is concerned about the use of Chinese medicine prescriptions, but it is also one of the directions that scholars from all sides are working hard to study. The Chinese Pharmacopoeia stipulates the dosage of a single Chinese medicine decoction piece, and the stipulated quality requirements ensure the effectiveness.

\section{Statement}

The material contained in the manuscript has not been previously published and is not being concurrently submitted elsewhere.

\section{Authorship}

Hualiang Chen participated in the conception and design of the manuscript, presided over this work and wrote this paper. Jingjing Yang participated in the discussion of the idea of the manuscript, revised and translated the manuscript.

\section{Conflicts of Interest}

The author declares that there is no conflict of financial/personal interest regarding the publishing of this paper.

\section{References}

[1] Liu, Q., Kong, D., Luo, J., Kong, W., Guo, W. and Yang, M. (2016) Quantitative and Fingerprinting Analysis of Atractylodes rhizome Based on Gas Chromatography with Flame Ionization Detection Combined with Chemometrics. Journal of Separa- 
tion Science, 39, 2517-2526. https://doi.org/10.1002/jssc.201501275

[2] Chen, Y., Wu, Y., Wang, H. and Gao, K. (2012) A New 9-Nor-Atractylodin from Atractylodes lancea and the Antibacterial Activity of the Atractylodin Derivatives. Fitoterapia, 83, 199-203. https://doi.org/10.1016/j.fitote.2011.10.015

[3] Wu, Y.X., Lu, W.W., Geng, Y.C., Yu, C.H., Sun, H.J., Kim, Y.J., et al. (2020) Antioxidant, Antimicrobial and Anti-Inflammatory Activities of Essential Oil Derived from the Wild Rhizome of Atractylodes macrocephala. Chemistry \& Biodiversity, 17, e2000268. https://doi.org/10.1002/jssc.201501275

[4] Liu, R., Tao, E., Yu, S., Liu, B., Dai, L., Yu, L., et al. (2016) The Suppressive Effects of the Petroleum Ether Fraction from Atractylodes lancea (Thunb.) DC. on a Collagen-Induced Arthritis Model. Phytotherapy Research, 30, 1672-1679.

https://doi.org/10.1002/ptr.5671

[5] Xu, K., Yang, Y.N., Feng, Z.M., Jiang, J.S. and Zhang, P.C. (2016) Six New Compounds from Atractylodes lancea and Their Hepatoprotective Activities. Bioorganic \& Medicinal Chemistry Letters, 26, 5187-5192.

https://doi.org/10.1016/j.bmcl.2016.09.069

[6] Plengsuriyakarn, T., Viyanant, V., Eursitthichai, V., Picha, P., Kupradinun, P., Itharat, A., et al. (2012) Anticancer Activities against Cholangiocarcinoma, Toxicity and Pharmacological Activities of Thai Medicinal Plants in Animal Models. BMC Complementary Medicine and Therapies, 12, Article No. 23. https://doi.org/10.1186/1472-6882-12-23

[7] Kubo, M., Nogami, M., Nishimura, M., Moriura, T. and Arichi, S. (1983) Origins, Processing, and Qualities of Crude Drugs (1). Preventive Effects of a Chinese Crude Drug, Zhu, on Experimental Stomach Ulcer and Its Pharmacological Evaluation. Yakugaku Zasshi, 103, 442-448.

[8] Hossen, M.J., Chou, J.Y., Li, S.M., Fu, X.Q., Yin, C., Guo, H., et al. (2019) An Ethanol Extract of the Rhizome of Atractylodes chinensis Exerts Anti-Gastritis Activities and Inhibits Akt/NF-кB Signaling. Journal of Ethnopharmacology, 228, 18-25. https://doi.org/10.1016/j.jep.2018.09.015

[9] Zhao, Y.L., Yang, X.W., Wu, B.F., Shang, J.H. and Liu, Y.P. (2019) Anti-Inflammatory Effect of Pomelo Peel and Its Bioactive Coumarins. Journal of Agricultural and Food Chemistry, 67, 8810-8818. https://doi.org/10.1021/acs.jafc.9b02511

[10] Oh, Y.C., Cho W.K., Jeong, Y.H., Im, G.Y., Yang, M.C., Hwang, Y.H., et al. (2012) Anti-Inflammatory Effect of Citrus Unshiu Peel in LPS-Stimulated RAW 264.7 Macrophage Cells. The American Journal of Chinese Medicine, 40, 611-629. https://doi.org/10.1142/S0192415X12500462

[11] Yu, X., Sun, S., Guo, Y., Liu, Y., Yang, D., Li, G., et al. (2018) Citri Reticulatae Pericarpium (Chenpi): Botany, Ethnopharmacology, Phytochemistry, and Pharmacology of a Frequently Used Traditional Chinese Medicine. Journal of Ethnopharmacology, 220, 265-282. https://doi.org/10.1016/j.jep.2018.03.031

[12] Wei, D., Ci, X., Chu, X., Wei, M., Hua, S. and Deng, X. (2012) Hesperidin Suppresses Ovalbumin-Induced Airway Inflammation in a Mouse Allergic Asthma model. Inflammation, 35, 114-21. https://doi.org/10.1007/s10753-011-9295-7

[13] Kawabata, A., Van, H.T., Nagata, Y., Fukuda, N. and Suzuki, T. (2018) Citrus kawachiensis Peel Powder Reduces Intestinal Barrier Defects and Inflammation in Colitic Mice. Journal of Agricultural and Food Chemistry, 66, 10991-10999. https://doi.org/10.1021/acs.jafc.8b03511

[14] Zhao, X.J., Xing, T.T., Li, Y.F. and Jiao, B.N. (2019) Analysis of Phytochemical Contributors to Antioxidant Capacity of the Peel of Chinese Mandarin and Orange 
Varieties. International Journal of Food Sciences and Nutrition, 70, 825-833. https://doi.org/10.1080/09637486.2019.1587743

[15] Walker, J.M., Maitra, A., Walker, J., Ehrnhoefer-Ressler, M.M., Inui, T. and Somoza, V. (2013) Identification of Magnolia officinalis L. Bark Extract as the Most Potent Anti-Inflammatory of Four Plant Extracts. The American journal of Chinese Medicine, 41, 531-544. https://doi.org/10.1142/S0192415X13500389

[16] Deng, Y., Han, X., Tang, S., Li, C., Xiao, W. and Tan, Z. (2018) Magnolol and Honokiol Attenuate Apoptosis of Enterotoxigenic Escherichia Coli-Induced Intestinal Epithelium by Maintaining Secretion and Absorption Homeostasis and Protecting Mucosal Integrity. Medical Science Monitor, 24, 3348-3356. https://doi.org/10.12659/MSM.910350

[17] Jacobo-Salcedo, M.R., Gonzalez-Espindola, L.A., Alonso-Castro, A.J., GonzalezMartinez, M.R., Domínguez, F. and Garcia-Carranca, A. (2011) Antimicrobial Activity and Cytotoxic Effects of Magnolia dealbata and Its Active Compounds. Natural Product Communications, 6, 1121-1124. https://doi.org/10.1177/1934578X1100600818

[18] Lin, M.H., Chen, M.C., Chen, T.H., Chang, H.Y. and Chou, T.C. (2015) Magnolol Ameliorates Lipopolysaccharide-Induced Acute Lung Injury in Rats through PPAR$\gamma$-Dependent Inhibition of NF-kB Activation. International Immunopharmacology, 28, 270-278. https://doi.org/10.1016/j.intimp.2015.05.051

[19] Chunlian, W., Heyong, W., Jia, X., Jie, H., Xi, C. and Gentao, L. (2014) Magnolol Inhibits Tumor Necrosis Factor- $\alpha$-Induced ICAM-1 Expression via Suppressing NF- $\kappa \mathrm{B}$ and MAPK Signaling Pathways in Human Lung Epithelial Cells. Inflammation, 37, 1957-1967. https://doi.org/10.1007/s10753-014-9928-8

[20] Yang, J., Wu, W., Wen, J., Ye, H., Luo, H., Bai, P., et al. (2017) Liposomal Honokiol Induced Lysosomal Degradation of Hsp90 Client Proteins and Protective Autophagy in Both Gefitinib-Sensitive and Gefitinib-Resistant NSCLC Cells. Biomaterials, 141, 188-198. https://doi.org/10.1016/j.biomaterials.2017.07.002

[21] Desta, K.T., Kim, G.S., Kim, Y.H., Lee, W.S., Lee, S.J., Jin, J.S., et al. (2016) The Polyphenolic Profiles and Antioxidant Effects of Agastache rugosa Kuntze (Banga) Flower, Leaf, Stem and Root. Biomedical chromatography, 30, 225-231. https://doi.org/10.1002/bmc.3539

[22] Li, H.Q., Liu, Q.Z., Liu, Z.L., Du, S.S. and Deng, Z.W. (2013) Chemical Composition and Nematicidal Activity of Essential Oil of Agastache rugosa against Meloidogyne incognita. Molecules (Basel, Switzerland), 18, 4170-4180. https://doi.org/10.3390/molecules 18044170

[23] Xu, W., Wang, N., Ding, H.R., Xu, J.J., Qu, Y.H., Pu, D., et al. (2017) Effects of Pogostemon Cablin on Gastrointestinal Function of Rats with Syndrome of Damp Retention in Middle-Jiao. China Journal of Chinese Materia Medica, 42, 4649-4655.

[24] Cui, B.W., Bai, T., Yang, Y., Zhang, Y., Jiang, M., Yang, H.X., et al. (2019) Thymoquinone Attenuates Acetaminophen Overdose-Induced Acute Liver Injury and Inflammation via Regulation of JNK and AMPK Signaling Pathway. The American journal of Chinese Medicine, 47, 577-594. https://doi.org/10.1142/S0192415X19500307

[25] Cui, Q., Wang, L.T., Liu, J.Z., Wang, H.M., Guo, N., Gu, C.B., et al. (2017) Rapid Extraction of Amomum tsao-ko Essential Oil and Determination of Its Chemical Composition, Antioxidant and Antimicrobial Activities. Journal of Chromatography B, Analytical Technologies in the Biomedical and Life Sciences, 1061-1062, 364-371. https://doi.org/10.1016/j.jchromb.2017.08.001 
[26] Shin, J.S., Ryu, S., Jang, D.S., Cho, Y.W., Chung, E.K. and Lee, K.T. (2015) Amomum tsao-ko Fruit Extract Suppresses Lipopolysaccharide-Induced Inducible Nitric oxide Synthase by Inducing Heme Oxygenase-1 in Macrophages and in Septic Mice. International Journal of Experimental Pathology, 96, 395-405. https://doi.org/10.1111/iep.12159

[27] Kim, J.G., Jang, H., Le, T.P.L., Hong, H.R., Lee, M.K., Hong, J.T., et al. (2019) Pyranoflavanones and Pyranochalcones from the Fruits of Amomum tsao-ko. Journal of Natural Products, 82, 1886-1892. https://doi.org/10.1021/acs.jnatprod.9b00155

[28] Minamizawa, K., Goto, H., Shimada, Y., Terasawa, K. and Haji, A. (2006) Effects of Eppikahangeto, a Kampo Formula, and Ephedrae herba against Citric Acid-Induced Laryngeal Cough in Guinea Pigs. Journal of Pharmacological Sciences, 101, 118-125. https://doi.org/10.1254/jphs.FP0060135

[29] Mei, F., Xing, X.F., Tang, Q.F., Chen, F.L., Guo, Y., Song, S., et al. (2016) Antipyretic and Anti-Asthmatic Activities of Traditional Chinese Herb-Pairs, Ephedra and Gypsum. Chinese Journal of Integrative Medicine, 22, 445-450. https://doi.org/10.1007/s11655-014-1952-x

[30] Zhang, B.M., Wang, Z.B., Xin, P., Wang, Q.H., Bu, H. and Kuang, H.X. (2018) Phytochemistry and Pharmacology of Genus Ephedra. Chinese Journal of Natural Medicines, 16, 811-28. https://doi.org/10.1016/S1875-5364(18)30123-7

[31] Vukovich, M.D., Schoorman, R., Heilman, C., Jacob, P. and Benowitz, N.L. (2005) Caffeine-Herbal Ephedra Combination Increases Resting Energy Expenditure, Heart Rate and Blood Pressure. Clinical and Experimental Pharmacology \& Physiology, 32, 47-53. https://doi.org/10.1111/j.1440-1681.2005.04152.x

[32] Statler, A.K., Maani, C.V. and Kohli, A. (2020) Ephedrine. StatPearls, Treasure Island, FL.

[33] Sioud, F., Ben Toumia, I., Lahme,r A., Khlifi, R., Dhaouefi, Z., Maatouk, M., et al. (2020) Methanolic Extract of Ephedra alata Ameliorates Cisplatin-Induced Nephrotoxicity and Hepatotoxicity through Reducing Oxidative Stress and Genotoxicity. Environmental Science and Pollution Research International, 27, 12792-12801. https://doi.org/10.1007/s11356-020-07904-3

[34] Zhu, X. and Chu, R.A. (1990) A Comparison of Anti-Arrhythmic Effects of Four Kinds of Rhizoma Seu Radix Nomopterygii. China Journal of Chinese Materia Medica, 15, 366-8385.

[35] Azietaku, J.T., Ma, H., Yu, X.A., Li, J., Oppong, M.B., Cao, J., et al. (2017) A Review of the Ethnopharmacology, Phytochemistry and Pharmacology of Notopterygium incisum. Journal of Ethnopharmacology, 202, 241-255.

https://doi.org/10.1016/j.jep.2017.03.022

[36] Liu, G., Lai, D., Liu, Q.Z., Zhou, L. and Liu, Z.L. (2016) Identification of Nematicidal Constituents of Notopterygium incisum Rhizomes against Bursaphelenchus $x y-$ lophilus and Meloidogyne incognita. Molecules (Basel, Switzerland), 21, 1276. https://doi.org/10.3390/molecules21101276

[37] Guo, N., Wu, J., Fan, J., Yuan, P., Shi, Q., Jin, K., et al. (2014) In Vitro Activity of Isoimperatorin, Alone and in Combination, against Mycobacterium tuberculosis. Letters in Applied Microbiology, 58, 344-349. https://doi.org/10.1111/lam.12195

[38] Wijerathne, C.U.B., Seo, C.S., Song, J.W., Park, H.S., Moon, O.S., Won, Y.S., et al. (2017) Isoimperatorin Attenuates Airway Inflammation and Mucus Hypersecretion in an Ovalbumin-Induced Murine Model of Asthma. International Immunopharmacology, 49, 67-76. https://doi.org/10.1016/j.intimp.2017.05.012

[39] Tong, K., Xin, C. and Chen, W. (2017) Isoimperatorin Induces Apoptosis of the 
SGC-7901 Human Gastric Cancer Cell Line via the Mitochondria-Mediated Pathway. Oncology Letters, 13, 518-524. https://doi.org/10.3892/ol.2016.5387

[40] Haque, M.A. and Jantan, I. (2017) Recent Updates on the Phytochemistry, Pharmacological, and Toxicological Activities of Zingiber zerumbet (L.) Roscoe ex Sm. Current Pharmaceutical Biotechnology, 18, 696-720. https://doi.org/10.2174/1389201018666171115115458

[41] Ali, B.H., Blunden, G., Tanira, M.O. and Nemmar, A. (2008) Some Phytochemical, Pharmacological and Toxicological Properties of Ginger (Zingiber officinale Roscoe): A Review of Recent Research. Food and Chemical Toxicology, 46, 409-420. https://doi.org/10.1016/j.fct.2007.09.085

[42] Chrubasik, S., Pittler, M.H. and Roufogalis, B.D. (2005) Zingiberis rhizoma: A Comprehensive Review on the Ginger Effect and Efficacy Profiles. Phytomedicine, 12, 684-701. https://doi.org/10.1016/j.phymed.2004.07.009

[43] Chang, J.S., Wang, K.C., Yeh, C.F., Shieh, D.E. and Chiang, L.C. (2013) Fresh Ginger (Zingiber officinale) Has Anti-Viral Activity against Human Respiratory Syncytial Virus in Human Respiratory Tract Cell Lines. Journal of Ethnopharmacology, 145, 146-151. https://doi.org/10.1016/j.jep.2012.10.043

[44] Nammi, S., Sreemantula, S. and Roufogalis, B.D. (2009) Protective Effects of Ethanolic Extract of Zingiber officinale Rhizome on the Development of Metabolic Syndrome in High-Fat Diet-Fed Rats. Basic \& Clinical Pharmacology \& Toxicology, 104, 366-373. https://doi.org/10.1111/j.1742-7843.2008.00362.x

[45] Saravanan, G., Ponmurugan, P., Deepa, M.A. and Senthilkumar, B. (2014) Anti-Obesity Action of Gingerol: Effect on Lipid Profile, Insulin, Leptin, Amylase and Lipase in Male Obese Rats Induced by a High-Fat Diet. Journal of the Science of Food and Agriculture, 94, 2972-2977. https://doi.org/10.1002/jsfa.6642

[46] Lee, W., Ku, S.K., Kim, M.A. and Bae, J.S. (2017) Anti-Factor Xa Activities of Zingerone with Anti-Platelet Aggregation Activity. Food and Chemical Toxicology, 105, 186-193. https://doi.org/10.1016/j.fct.2017.04.012

[47] Bhandare, A.M., Kshirsagar, A.D., Vyawahare, N.S., Hadambar, A.A. and Thorve, V.S. (2010) Potential Analgesic, Anti-Inflammatory and Antioxidant Activities of Hydroalcoholic Extract of Areca catechu L. Nut. Food and Chemical Toxicology, 48, 3412-3417. https://doi.org/10.1016/j.fct.2010.09.013

[48] Liu, Y.J., Peng, W., Hu, M.B., Xu, M. and Wu, C.J. (2016) The Pharmacology, Toxicology and Potential Applications of Arecoline: A Review. Pharmaceutical Biology, 54, 2753-2760. https://doi.org/10.3109/13880209.2016.1160251

[49] Peng, W., Liu, Y.J., Wu, N., Sun, T., He, X.Y., Gao, Y.X., et al. (2015) Areca catechu L. (Arecaceae): A Review of Its Traditional Uses, Botany, Phytochemistry, Pharmacology and Toxicology. Journal of Ethnopharmacology, 164, 340-356.

https://doi.org/10.1016/j.jep.2015.02.010

[50] Pithayanukul, P., Nithitanakool, S. and Bavovada, R. (2009) Hepatoprotective Potential of Extracts from Seeds of Areca catechu and Nutgalls of Quercus infectoria. Molecules (Basel, Switzerland), 14, 4987-5000.

https://doi.org/10.3390/molecules14124987

[51] Abbas, G., Naqvi, S., Erum, S., Ahmed, S., Attaur, R. and Dar, A. (2013) Potential Antidepressant Activity of Areca catechu Nut via Elevation of Serotonin and Noradrenaline in the Hippocampus of Rats. Phytotherapy Research, 27, 39-45. https://doi.org/10.1002/ptr.4674

[52] Sakaue, Y., Domon, H., Oda, M., Takenaka, S., Kubo, M., Fukuyama, Y., et al. (2016) Anti-Biofilm and Bactericidal Effects of Magnolia Bark-Derived Magnolol 
and Honokiol on Streptococcus mutans. Microbiology and Immunology, 60, 10-16. https://doi.org/10.1111/1348-0421.12343

[53] Zhang, W.W., Li, Y., Wang, X.Q., Tian, F., Cao, H., Wang, M.W., et al. (2005) Effects of Magnolol and Honokiol Derived from Traditional Chinese Herbal Remedies on Gastrointestinal Movement. World Journal of Gastroenterology, 11, 4414-4418. https://doi.org/10.3748/wjg.v11.i28.4414

[54] Nakai, Y., Kido, T., Hashimoto, K., Kase, Y., Sakakibara, I., Higuchi, M., et al. (2003) Effect of the Rhizomes of Atractylodes lancea and Its Constituents on the Delay of Gastric Emptying. Journal of Ethnopharmacology, 84, 51-55.

https://doi.org/10.1016/S0378-8741(02)00260-X 